\title{
KAFKA, NIETZSCHE E DUAS PARÁBOLAS ${ }^{1}$
}

Henry Burnett (UNIFESP)

hmburnett@gmail.com

Resumo: $\mathrm{O}$ artigo desenvolve uma leitura em paralelo de dois textos: um trecho de Der tolle Mensch (§ 125 d'A gaia ciência, de Nietzsche) e a parábola Ein commentar (aforismo de Kafka). Não procurando realizar uma análise comparada, procura-se apontar algumas aproximações e alguns distanciamentos. Como mediadores desta tentativa de leitura, utilizamos uma carta de Walter Benjamin e os comentários de Modesto Carone sobre a parábola de Kafka.

Palavras-chave: Nietzsche; Kafka; filosofia alemã; niilismo.

Ao comentar sobre as viagens de Kafka pela Europa, e sobre todo o panorama sócio-político dentro do qual o escritor tcheco viveu e produziu, o tradutor e comentador brasileiro Modesto Carone destacou algo importante acerca da relação do escritor com a tradição germânica, principalmente no que toca a uma tríade de autores comumente posta lado a lado: "Foi esta a Europa cujos valores culturais sofreram um baque com os escritos de Nietzsche, Marx e Freud. As

\footnotetext{
${ }^{1}$ Recebido: 28-08-2016/Aceito: 08-12-2016/ Publicado on-line: 19-01-2017.

${ }^{2}$ Henry Burnett é Professor Associado da Universidade Federal de São Paulo, Guarulhos, SP, Brasil.
} 
revoluções de pensamento desencadeadas por esse trio evidentemente deixaram marcas visíveis na obra de Kafka" (CARONE 2011, 11-12). Seu comentário já eliminaria qualquer dúvida sobre a questão da influência de Nietzsche sobre o escritor tcheco, cuja obra foi redigida integralmente em alemão. ${ }^{3}$ Mas existem ainda outros indícios hoje bastante conhecidos sobre a influência específica de Nietzsche sobre Kafka. Numa carta de uma colega da escola primária de Kafka, Selma Robitschek, endereçada a Max Brod, lemos: "Frequentemente nos sentávamos embaixo deste carvalho, nós crianças, Franz e eu, e ele lia Nietzsche em voz alta”. Noutro comentário encontramos ainda: "O tendo descoberto ainda no ginásio, Kafka se manteve fiel ao pensamento de Nietzsche até sua morte" (respectivamente KAFKA apud SKOWRON 2005, 293-294 e KURZ 1988, 138).

Então, o que os nomes de Nietzsche e Kafka juntos poderia ainda suscitar? Uma questão que, aparentemente, está respondida, e pode ser resumida da seguinte maneira: a tensão de suas obras em relação com a época em que foram escritas os irmana em muitos aspectos, seja narrativos, estilísticos e até mesmo em traços confessionais. Mas além das marcas deixadas pelos três autores mencionados sobre Kafka, certamente não poderíamos negar as particularidades do autor de A metamorfose. Carone também aponta para esse dado: "(Em sentido contrário, é fútil imaginar que a obra kafkiana pudesse manter-se 'inocente', ou mesmo 'ininteligível', no sentido ideológico, diante do que estava acontecendo.)" (CARONE 2011, 12).

\footnotetext{
${ }^{3}$ Sobre as leituras de Nietzsche por Kafka ver, por exemplo, Anderson (1991).
} 
Em seu mais recente trabalho sobre o escritor tcheco, o citado Franz Kafka essencial, Modesto Carone acrescenta às muitas traduções que fez, comentários inéditos - e reveladores - aos textos já publicados, mas também novas análises de alguns escritos traduzidos especialmente para o volume. O maior destaque, sem dúvida, é o conjunto de aforismos que integra o livro e que, no entanto, já haviam sido publicados no número de estreia da revista Serrote, em 2009. Num trabalho sobre Nietzsche e Kafka seria quase natural pensar em uma correlação desses breves textos à cata de similitudes estilísticas e temáticas com os aforismos de $\mathrm{Ni}$ etzsche, tão determinantes a partir de Humano, demasiado humano. Ainda que Nietzsche os tenha utilizado de modo mais intenso, os aforismos de Kafka revelam que o autor foi igualmente competente no estilo conciso e lapidar que consagrara Nietzsche; ${ }^{4}$ mas a obviedade seria inescapável, não fosse por um texto de pouco mais de dez linhas intitulado "Desista!", ou "Um comentário", que precede os aforismos e é chamado pelo comentador de parábola. É sobre essa parábola que gostaria de tecer algumas observações a partir de sua proximidade com um célebre texto de Nietzsche; tratase de um dos seus mais comentados aforismos: o $\$ 125$ d'A gaia ciência. Lido apenas fisicamente, não passaria de um fato de rua quase corriqueiro, uma narrativa próxima de uma narrativa breve, no entanto, ele guarda uma das mais importantes teses da obra de Nietzsche: a conhecida tese sobre a "morte de Deus". Nele o autor narra o momento em que

\footnotetext{
${ }^{4}$ Sobre a utilização da forma aforística nos dois autores, Günther Anders afirma em referência à coletânea Ele, de 1920, que se trata de uma "Sequência de aforismos ou fragmentos de pensamentos que, no entanto, não formam um projeto filosófico como os fragmentos de Nietzsche"., in: ANDERS 2007, 152).
} 
um homem louco sai ao mercado público à procura de Deus. Eis o trecho inicial e mais importante para nós, e que dá o tom de todo o restante do aforismo.

O homem louco. - Não ouviram falar daquele homem louco que em plena manhã acendeu uma lanterna e correu ao mercado, e pôs-se a gritar incessantemente: "Procuro Deus! Procuro Deus!"? - E como lá se encontrassem muitos daqueles que não criam em Deus, ele despertou com isso uma grande gargalhada. Então ele está perdido? Perguntou um deles. Ele se perdeu como uma criança? Disse um outro. Está se escondendo? Ele tem medo de nós? Embarcou num navio? Emigrou? - gritavam e riam uns para os outros. O homem louco se lançou para o meio deles e trespassou-os com seu olhar. "Para onde foi Deus?", gritou ele, "já lhes direi! Nós o matamos - vocês e eu. Somos todos seus assassinos! (NIETZSCHE 2001, 147).

Procedimento estilístico muito frequente no conjunto da obra, a narrativa em tom de parábola permite leituras tão díspares que podem chegar facilmente a antagonismos, ou a leituras simplistas, como as que veem no enunciado a verdadeira morte do Criador operada por um simplório anticristo. Justamente quando deveria enunciar algo de extrema gravidade, Nietzsche serve-se da alegoria narrativa, deixando-o em aberto - hoje, sabemos, proposital e conscientemente - para as mais variadas interpretações. Sua intenção, imagina-se pelo teor experimental do enunciado, era fornecer ao leitor uma potente formulação, a partir da qual o homem moderno poderia considerar sua própria experiência no mundo que se abria sob a alcunha de modernidade. Dava-lhes uma ferramenta, como se diria mais tarde da obra de Nietzsche. No entanto, a despeito da possível intenção aberta, o aforismo, de muitas maneiras, é um emblema do que viria adiante como confirmação histórica.

Como Nietzsche, Kafka utilizou-se da metáfora como 
uma de suas maiores forças, como um "elemento constitutivo", no dizer de Ernst Cassirer. Cabe então revelar na íntegra o ponto de partida deste artigo, a parábola "Ein commentar".

Era de manhã bem cedo, as ruas limpas e vazias, eu ia para a estação ferroviária. Quando confrontei um relógio de torre com o meu relógio, vi que já era muito mais tarde do que havia acreditado, precisava me apresar bastante; o susto dessa descoberta fez-me ficar inseguro no caminho, eu ainda não conhecia bem aquela cidade, felizmente havia um guarda por perto, corri até ele e perguntei-lhe sem folego pelo caminho. Ele sorriu e disse:

- De mim você quer saber o caminho?

- Sim - eu disse -, uma vez que eu mesmo não posso encontrá-lo.

- Desista, desista - disse ele e virou-se com um grande ímpeto, como as pessoas que querem estas a sós com o seu riso (KAFKA 2011, 183).

É o próprio Carone quem nos dá os caminhos de sua leitura. Se faz necessário, como o leitor poderá constatar, citar seu comentário na íntegra.

O texto desta parábola de 1922 recebeu também o título de "Um comentário" ("Ein commentar"). É provável que este último referiase diretamente ao esboço de uma carta de Kafka a Franz Werfel, na qual ele pretendia demonstrar o tipo de elaboração parabólica comum aos comentários do talmude. "Desista!" é considerada uma obra emblemática do estilo tardio de Kafka, narrada em primeira pessoa por alguém que quer encontrar o caminho para a estação ferroviária numa cidade desconhecida. Seu atraso no tempo leva-o a se desorientar no espaço. Ou pôr de lado aquela busca. Essa observação é acompanhada por um riso misterioso, que torna as ações do guarda mais incompreensíveis ainda.

O texto está construído em torno da discrepância entre as expectativas do narrador em relação ao policial para resolver o dilema e o desapontamento enfático (na verdade, ridículo) dessas expectativas: a discrepância encoraja o leitor a duvidar do retrato realista do texto e a ultrapassar seu nível literal, levando-o a especular sobre os sentidos 
metafísicos ou simbólicos que a história está escondendo atrás da imagem central. A tentativa de traduzir a superfície literal para qualquer núcleo de significado (biográfico, psicanalítico, histórico, religioso ou experimental) é inútil: o que realmente fica ressoando no conto é o riso escarninho do guarda (CARONE 2011, 181).

Tomadas as devidas diferenças, o comentário de Carone ao emblemático texto de Kafka poderia ser utilizado quase sem retoques em relação ao aforismo de Nietzsche. $\mathrm{O}$ falso realismo, a impossibilidade de circunscrevê-lo a partir de interpretações fechadas e a necessidade inescapável de buscar-lhe o sentido metafísico ou simbólico se aplica ao aforismo de modo inequívoco. Com tantas semelhanças, a única via possível de aproximação é rastrear suas diferenças, é quando a leitura desses dois fragmentos se torna ainda mais estimulante. Passemos à segunda parte deste breve exercício, mas não sem antes retomar uma importante observação de Günther Anders, destacado intérprete de Kaf$\mathrm{ka}$, sem a qual nenhuma das proposições aqui supostas faria sentido.

A inconsequência das "ordens sem ordenante" foi visível com nitidez a apenas dois homens, com exceção dos niilistas russos: Nietzsche e Kafka. De fato, foi Nietzsche, apesar das amplitude do movimento naturalista do século XIX, o único de sua geração que teve em mente a questão da legitimidade da moral em geral, quando submeteu à sua crítica a moral cristã. Seus títulos (sic) Deus está morto e Além do bem e do mal são, em última análise, apenas duas variações sobre um mesmo tema.

A situação "Deus está morto" é o ponto de partida de tudo o que Kafka escreveu (ANDERS 2007, 113).

\section{AS PARÁBOLAS}

O louco de Nietzsche pode ser visto como seu próprio au- 
tor, isto é, não tem nada de alucinado. Se é chamado de louco é apenas para revelar que, naquele momento, só um "louco" procuraria alguma esperança em meio à derrocada de sentido, dos valores que sangravam diante de uma Europa imersa no niilismo. Para Nietzsche, tal quadro era irrecuperável, mas seu diagnóstico não é menos irônico por isso. Note-se que, em meio à zombaria dos demais, é ele mesmo, o louco, que assombra aqueles para quem sua busca era vã, ele mesmo comunica aos homens normais que já não havia normalidade possível. Ele é a razão invertida.

Em Kafka, a figura do homem perdido e sem rumo é a representação de qualquer um de nós. A estação ferroviária pode ser uma metáfora de Deus, que na parábola de Kafka surge como o único lugar seguro em meio a uma cidade que não se conhece bem, isto é, que não se sabe onde vai dar, que nos assombra porque já difere do sentido do humano. A cidade desconhecida é a modernidade vista pela lente precoce de Nietzsche. O louco e o desnorteado são o mesmo homem, filtrados, primeiro, por um diagnóstico segundo o qual era loucura procurar Deus depois de tê-lo extinguido, e depois por uma aparente normalidade, que ofusca exatamente a demência que já contaminava toda a Europa. Nietzsche antevê, Kafka "simplesmente" narra. Narrador do indizível nietzschiano, o homem perdido ainda busca uma saída, não por acaso na figura da lei, do juízo, da norma, da segurança; então não apenas a forma metafórica dos dois autores se expõe, mas também algo que os liga talvez ainda mais profundamente vem à tona: a ironia.

A personagem de Nietzsche prenuncia o fim de qualquer esperança, mas não sem antes pôr na boca dos descrentes o riso escarninho de um nervosismo coletivo, 
embora ainda ingênuo - os descrentes, desocupados em praça pública, não tem para onde ir, e não despertam dessa apatia diante do louco, apenas riem dele como se aquela busca não fizesse nenhum sentido. É bastante curioso que o homem desesperado soubesse desde o início da narrativa que "Deus estava morto", mas, ainda assim, interrogasse os demais, supondo ainda um fio de razão em meio à sua própria elucubração, ou antes supõe ou deseja que sua loucura não se confirme.

O desnorteado de Kafka tem seu quê de desespero, mas, diferente do louco, só desperta para sua própria condição quando confronta o relógio da praça com o seu. Só depois dessa descoberta ele se assusta, só depois que o tempo parece curto e limitado demais para qualquer encontro. Quando o louco sai ao mercado o narrador oculto diz que "era plena manhã", da mesma forma que o desnorteado informa desde o início que "era de manhã bem cedo". Em ambos os casos tomaram consciência de seus desamparos à luz do dia, e não sob o escuro da noite, que poderia velar o real da miséria exposta. A distância entre os dois textos define o foco dos narradores: no caso de Nietzsche estamos no momento crucial da descoberta da grande interrogação moderna, prenunciada pelo fim da esperança messiânica cujo desfecho se dá em plena derrocada mítica, envoltos no manto da industrialização primitiva; em Kafka estamos imersos nos resultados das perguntas inseguras formuladas por Nietzsche, quando todas as esperanças jaziam sob escombros.

Certamente o inacabamento do fragmento de Kafka não se encontra no elaborado aforismo de Nietzsche. Isso se nota na profusão de possibilidades que as interrogações do 
homem louco suscitam no leitor, bastaria pensarmos sobre o destino-esperança do Deus destroçado, forjado entre muitas metáforas que beiram o risível: perdido, escondido, amedrontado, embarcado e até mesmo emigrado estaria esse Deus obscuro. Cada termo deslocando a leitura para muitas direções. O desnorteado kafkiano parece saber onde vai, tem um destino - ainda que indefinido. Sua busca não é por um ente, mas pelo local desse embarque enigmático que nunca poderá ser efetivado. $\mathrm{O}$ susto dele é distinto da revelação da morte da esperança em Nietzsche; a personagem só se desestrutura quando o tempo se fecha, diminui, daí então vem a grande correria, a tentativa desesperada de alcançar a saída. Os personagens de Nietzsche se refestelam na praça, tem tempo de sobra, ou acham que tem. Não há pressa, porque não se sabe o que virá. Em Kafka o tempo já foi, e é do susto dessa descoberta que nasce o desespero, a constatação do limite, só que pleno de consciência.

\section{UMA CARTA DE BENJAMIN SOBRE KAFKA}

De que maneira poderíamos reler esses dois textos sem pesar a mão nessa comparação, sem imaginar que Kafka estivesse reescrevendo Nietzsche, mas ao mesmo tempo sem perder suas ligações quase imperceptíveis? Se considerarmos que a ironia sobre a loucura no aforismo de Nietzsche quer chegar exatamente no seu oposto, isto é, que há uma profunda sabedoria em seu jogo, o mesmo não se poderia dizer de Kafka. Nele não há nenhuma saída, até mesmo sua interpretação é intricada ao nível do absurdo. Poderíamos dizer que não há nenhuma tese em Kafka, e que é a própria narrativa que confere o grau de dificuldade de sua exegese. 
É quando um dos grandes leitores de ambos pode lançar alguma luz sobre suas obras e talvez sobre seu silencioso diálogo: Walter Benjamin.

Acompanhemos algumas reflexões de Benjamin sobre Kafka, numa carta enviada a Gershom Scholem a propósito do lançamento de uma biografia do tcheco escrita por seu amigo Max Brod.

Não nos interessa aqui a profunda crítica que Benjamin dirige a Brod e à sua necessidade de expor um nível de intimidade tolo em relação a Kafka, mas, da metade da carta para o final, o próprio Benjamin avisa que suas observações sobre Kafka "vão sugerir a você [Scholem] um aspecto novo, mais ou menos independente das minhas reflexões anteriores" (BENJAMIN 1993, 104). De fato, as observações de Benjamin podem ser tomadas como complemento ao ensaio "Franz Kafka", dedicado ao escritor, embora a carta tenha sido escrita nove anos antes do ensaio. Suas observações, como espero poder mostrar, tocam diretamente no núcleo deste comentário.

De alguma maneira a praça onde Nietzsche põe em cena o louco guarda algo de sua profunda crítica à modernidade. A mensagem gritada em público tende a esgotar um período e dar início a outro, justamente a modernidade e suas calamidades urbanas. Portanto não é apenas uma referência à ágora grega que está em pano de fundo, talvez antes e principalmente Nietzsche faça o anúncio tendo em mente a praça moderna, ou seja, um símbolo das cidades que floresciam, e contra as quais ele mais de uma vez fez referências. Quando Benjamin cita uma longa passagem de um físico chamado Eddington, extraída do texto "Imagem do mundo oferecida pela física", o faz como um dispositivo 
analógico para reiterar que a impossibilidade de um físico entrar por uma porta - e com todas as imagens forjadas no texto - se liga de modo direto com a experiência do próprio Kafka. Não por acaso, Benjamin considera o homem moderno um duplo desse físico imerso nesse labirinto intransponível. "Não conheço na literatura nenhuma passagem que mostre no mesmo grau o gesto de Kafka" (BENKAMIN 1993, 104).

Para Benjamin, as mais "incompreensíveis" narrativas de Kafka caberiam na descrição aporética do físico; é nesse momento do texto que Benjamin insere a tese da transformação da tradição judaica em Kafka: "Quando portanto se diz, como acabo de fazer, que as experiências correspondentes de Kafka se encontravam numa tensão violenta com as experiências místicas, diz-se somente uma meia-verdade" (BENJAMIN 1993, 105). Benjamin, de fato, vai além de uma demonstração dessa hipótese, ele diz mesmo que Kafka precisou apelar para a tradição judaica para poder se defrontar com a realidade, teoricamente na aporia física e, concretamente, na técnica da guerra.

Não é de hoje que as ambiguidades de Nietzsche acerca do valor da ascese religiosa são objeto de atenção. Em vários momentos ele afirmou coisas como essas, retiradas de $\mathrm{Hu}$ mano, demasiado humano: "Poder-se-ia abrir mão da arte, mas com isso não se perderia a aptidão aprendida dela: assim como se pode abrir mão da religião, mas não das intensidades e elevações de ânimo adquiridas através dela” (NIETZSCHE 1974, 113). O comentário de Benjamin sobre a tensão kafkiana cria nesse momento uma reveladora interface com a tese de Nietzsche: "O que de fato - e num sentido preciso - é maluco em Kafka, é que este recentíssi- 
mo mundo de experiência lhe foi confidenciado justamente pela tradição mística” (BENJAMIN 1993, 105).

O louco de Nietzsche é também um anunciador. Um mensageiro. Seria impossível não pensar nessa cadeia entre Deus, boa-nova, desagregação, loucura e fim das esperanças. $\mathrm{O}$ anunciador proclama aquilo que não poderia ser dito, aquilo que todos gostariam de ocultar. Isso será quase idêntico em Kafka, como tentarei mostrar. Vejamos como encerra a carta de Benjamin, e deixemos quase em aberto o que ela pode suscitar a respeito da parábola de Nietzsche:

É por isso que em Kafka não se pode mais falar em sabedoria. Sobram os produtos da sua desintegração. Há dois deles: um é o rumor das coisas verdadeiras (uma espécie de jornal-sussurro teológico, que trata de coisas desacreditadas e obsoletas); o outro produto dessa diátese é a tolice, que de fato dilapidou fundo o conteúdo próprio à sabedoria, mas em compensação guarda o lado agradável e sereno que foge sempre e em qualquer parte ao rumor (BENJAMIN 1993, 106).

$\mathrm{Na}$ parábola de Kafka não há sabedoria, o "louco" é apenas um cidadão, como qualquer um de nós; irremediavelmente comum. Daí resulta a dificuldade, fosse o caso, de igualar as duas personagens; neles há um abismo chamado esperança. Se Nietzsche tinha alguma, ainda que nutrida por um projeto pessoal de transvaloração, em Kafka nada sobra, nem como projeto; nenhuma ajuda, por isso o guarda lhe dá as costas, irônico e impassível: "Para Kafka era indubitável [...]: primeiro, que alguém, para ajudar precisa ser um tolo; segundo, que só a ajuda de um tolo é realmente ajuda. Incerto é apenas: ela ainda enleia o homem?" (BENJAMIN 1993, 106).

Decerto Kafka não pensava no homem louco de Nietzsche quando escreveu sua parábola, mas o refinamento dos 
dois textos e a riqueza de suas imagens abre um campo de possibilidades de grande envergadura, mesmo que apenas como um exercício de leitura. Não é à toa que Benjamin surge como um privilegiado mediador entre as leituras e suas aparentes similitudes; poucos leram tão bem, e no calor da hora, dois autores que só seriam criticamente estudados e compreendidos décadas depois.

As observações de Benjamin sobre Kafka acabam por revelar algo que o comentário supracitado de Modesto Carone havia antecipado: "A tentativa de traduzir a superfície literal para qualquer núcleo de significado (biográfico, psicanalítico, histórico, religioso ou experimental) é inútil”, mas também não deixa de ser útil quando aplicado sobre o aforismo de Nietzsche, embora a recepção tenha tratado de explicitar sua extensão filosófica e sua importância histórica para a história do cristianismo.

Em ambos se revela uma sensação desesperada da agonia, algo que em Nietzsche foi explorado com extrema finura e que, em Kafka, ganha na alegoria da indefinição sua grande força. Não resta dúvida que se trata, em ambos os casos, de um deliberado esforço para expor os limites da desesperança que encobria a Europa e logo contaminaria o mundo do pós-guerra. No limite, o final da carta de Benjamin sintetiza o legado de Kafka, mas acaba por sepultar o fio de esperança do programa de Nietzsche - pelo menos em sua época - deixando para nós a herança do indefinível; eis as palavras de Benjamin: "Assim, pois, conforme diz Kafka, existe uma esperança infinita, só que não para nós. Esta frase contém na realidade a esperança de Kafka. Ela é a fonte de sua irradiante serenidade" (BENJAMIN 1993, 106). Se a leitura desses dois autores hoje pode reativar - 
ou manter vivo - o legado dessas duas forças, é apenas, e novamente, se funcionar como uma tarefa de levar às últimas consequências aquilo que para Benjamin era fundamental em Kafka e, não se pode negar, para Nietzsche na mesma medida.

Para fazer justiça à figura de Kafka em sua pureza e peculiar beleza não se pode nunca perder de vista uma coisa: ela é a de um fracassado. As circunstâncias desse fracasso são múltiplas. Seria possível dizer: uma vez seguro do malogro final, no caminho ele conseguia tudo como em sonho. Nada mais memorável que o fervor com que Kafka sublinhou seu fracasso (BENJAMIN 1993, 106).

Abstract: The article develops a parallel reading of two texts: an excerpt from Der tolle Mensch ( $\$ 125$ of The Gay Science, Nietzsche) and parable Ein commentar (Kafka's aphorism). Not looking to perform a comparative analysis to point out some approaches and some distances. As a mediator of this attempt to read, we use a letter from Walter Benjamin and Modesto Carone's comments about the parable by Kafka.

Keywords: Nietzsche; Kafka; German philosophy; nihilism.

\section{REFERÊNCIAS}

ANDERS, Günther. Kafka: pró e contra (tradução, posfácio e notas de Modesto Carone). São Paulo: Cosac Naif, 2007.

ANDERSON, Mark. "Juifs dionysiens: lectures de Nietzsche à Prague, autour de Brod et de Kafka". In: BOUREL, D. et LE RIDER J. (éd.) De Sils-Maria à Jérusalem. Nietzsche et le judaïsme: les intellectuelles juifs et Nietzsche. Paris: Cerf, 1991.BENJAMIN, Walter. "Carta a Gershom Scholem" (tradução do alemão e notas de Modesto Carone). In: Revista Novos Estudos, CEBRAP, $\mathrm{n}^{\circ}$ 35, março 1993. 